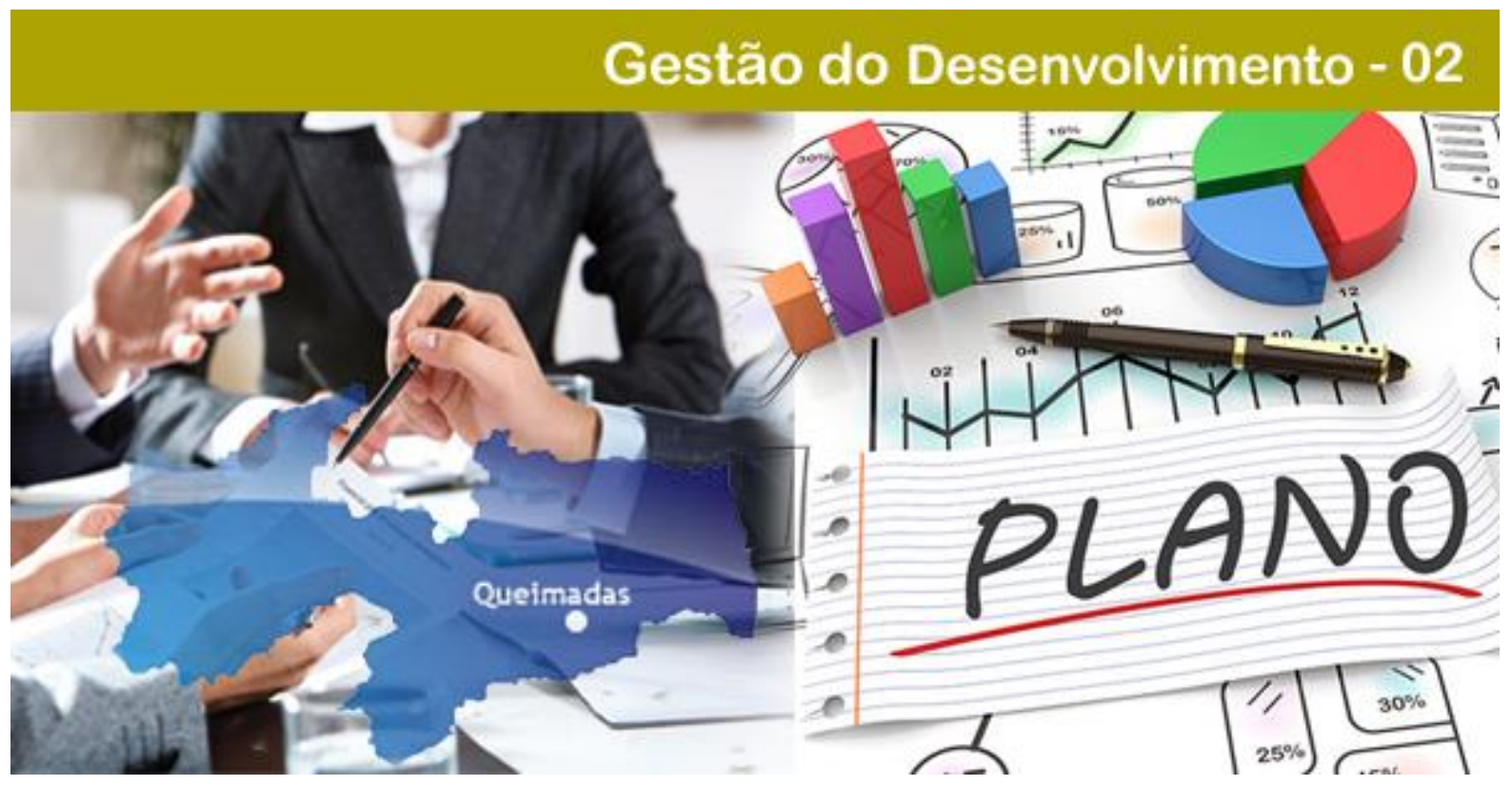

\title{
PLANEJAMENTO E DESENVOLVIMENTO LOCAL SUSTENTÁVEL: A EXPERIÊNCIA CONSTRUÇÃO DO PLANO DIRETOR PARTICIPATIVO DE QUEIMADAS-PARAÍBA, BRASIL
}

\section{Danilo Raimundo de Arruda}

Doutor em economia pela Universidade Federal do Rio de Janeiro (UFRJ). Pesquisador da Rede de Pesquisa em Arranjos e Sistemas Produtivos e Inovativos Locais (RedeSist), Instituto de Economia/UFRJ. E-mail: daniloarruda@redesist.ie.ufrj.br.

Elaine Cavalcante Peixoto Borin

Doutora em Planejamento Urbano e Regional pela Universidade Federal do Rio de Janeiro (UFRJ). Professora adjunta da Faculdade de Engenharia da Universidade do Estado do Rio de Janeiro/UERJ. E-mail: elaine.borin@ig.com.br.

Pablo Aurélio Lacerda de Almeida Pinto

Doutor em Economia pelo Programa de Pós-Graduação em Economia da Universidade Federal de Pernambuco (PIMES/UFPE). Professor da Universidade de Pernambuco (UPE). E-mail: pabloaurelioap@ hotmail.com.

\section{Severino José de Lima}

Doutor em Ciências Sociais em Desenvolvimento, Agricultura e Sociedade pela Universidade Federal Rural do Rio de Janeiro (UFRRJ). Professor do Departamento de Sociologia da Universidade Federal de Campina Grande (UFCG).E-mail: lima.severino2012@gmail.com.

Resumo: O objetivo deste trabalho é apresentar a experiência de construção do Plano Diretor Participativo do Município de Queimadas-Paraíba-Brasil. Este plano constitui-se num instrumento de planejamento municipal para o desenvolvimento sustentável. Foram combinados vários procedimentos metodológicos para esta investigação: revisão da literatura, pesquisa documental (Plano Diretor Participativo de Queimadas-PDPQ) e pesquisa de campo com realização de entrevista semiestruturada. Os resultados apontam para a fragilidade dos recursos humanos e sociais, a incipiência do capital social e, ainda, a ausência de uma estrutura administrativa comprometida com a coisa pública. Esses fatores colocam-se como impeditivos para uma construção participativa e para os desdobramentos de um Plano Diretor, qual seja, a sua fase de execução. Portanto, a participação cidadã nos processos decisórios, o aprendizado social e os recursos humanos e sociais (o capital

\section{POLÊM!CA | Revista Eletronica da Uej}


social) são elementos fundamentais para construção do instrumento de transformação social. Esses são elementos balizadores do planejamento e do desenvolvimento territorial sustentável.

Palavras-chave: Planejamento. Desenvolvimento Local. Capital Social. Participação Cidadã.

\section{PLANNING AND SUSTAINABLE LOCAL DEVELOPMENT: THE CONSTRUCTION EXPERIENCE OF THE PARTICIPATIVE MÁSTER PLAN OF QUEIMADAS-PARAÍBA, BRAZIL}

Abstract: The objective of this paper is present the Participative Director Plan construction in Queimadas city in the Paraíba state, Brazil. This is a municipal plane for sustainable development of the city. In this work, there are different methodological analysis: literature review, documentary and field research. The results show a humans, social resources and social capital fragilities. Furthermore, the absence of compromised administrative structure with publics questions. These factors are barriers for Participative Director Plan construction. Although the mobilization and citizen participation in the decision-making process, showed fundamental for development of instruments of social transformation. These benchmarks are elements of planning and territorial development sustainable.

Keywords: Planning. Local Development. Social Capital. Citizen Participation.

\section{Introdução}

O objetivo deste trabalho é apresentar a experiência de construção do Plano Diretor Participativo do Município de Queimadas-Paraíba. Este plano constitui-se num instrumento de planejamento municipal para o desenvolvimento territorial sustentável. A experiência de construção de um plano diretor em uma pequena cidade da Paraíba merece ser refletida diante dos problemas urbanos (ambientais, sociais, espaciais, educacionais, de saúde, saneamento básico, e outros) que cada vez mais se afloram no território brasileiro (e que são comuns às cidades de pequeno, médio, grande porte e as metrópoles) e na perspectiva de se retomar o debate sobre o Estatuto da Cidade - Lei 10.257/2001 (BRASIL, 2001) e a Constituição Federal (BRASIL, 1988).

O Ministério das Cidades, em "Plano Diretor Participativo: Guia para elaboração pelos municípios e cidades (2004)" sugere o planejamento participativo como o caminho para se construir cidades melhores e mais justas. O pressuposto do documento do Ministério é de que todos os membros da sociedade estão aptos a participarem do planejamento territorial de seus municípios.

A premissa é que um pequeno município traz elementos importantes para refletir os problemas sociais e urbanos de planejamento do desenvolvimento territorial. Esses problemas são comuns aos mais variados portes de município e requer para a sua superação a participação cidadã e o fortalecimento dos recursos humanos e sociais. Esses fatores são pressupostos e supostos para a boa prática do planejamento e da reivindicação de sua execução.

\section{POLÊM!CA | Revista Eletronica da ver}


Por participação se entende, antes de tudo, o direito de decidir, de assumir o controle de seu próprio destino e não de ser controlado por outrem. Segundo Bordenave (1994) a participação pode ser aprendida e aperfeiçoada pela prática e pela reflexão. A sua qualidade eleva-se quando os participantes de um processo, como o de planejamento da cidade, aprendem a conhecer a sua realidade; aprendem a refletir e analisar os problemas e as contradições reais ou aparentes e buscam construir alternativas de superação; aprendem a identificar premissas subjacentes e a antecipar consequências; aprendem a distinguir os efeitos e as causas, observação de inferências e fatos de planejamento no processo de saber mais para transformar a realidade.

O capital social é outra variável fundamental do desenvolvimento das sociedades contemporâneas que emergem, enquanto sociedades, em redes e do conhecimento (CASTELLS, 1999). É, também, um pré-requisito para todas as formas de empreendimento em grupo, que têm como lugar uma sociedade moderna, por ser um atributo coletivo. É gerador de riqueza e tem importância impar para a economia nacional (FUKUYAMA, 2000; PUTNAM, 1996; BOURDIEU, 1998; TOCQUEVILLE, 1985).

O capital social, portanto, diz respeito a características da organização social, como confiança, normas e sistemas, que contribuem para aumentar a eficiência da sociedade. É uma espécie de capital que facilita a cooperação espontânea. Cria um ambiente de associativismo cívico (PUTNAM, 1996).

É com base nesses elementos que iremos analisar a experiência de construção do Plano Diretor do Município de Queimadas ${ }^{1}$, Estado da Paraíba/Brasil. O município ${ }^{2}$ está localizado em pleno semiárido nordestino, mais especificamente, no Planalto da Borborema, fazendo fronteira ao norte com Campina Grande (segundo maior centro urbano industrial e de serviços do Estado da Paraíba). O Instituto Brasileiro de Geografia e Estatística (IBGE) situa Queimadas na mesorregião geográfica do Agreste da Paraíba e na microrregião de Campina Grande. O município é cortado pela BR 104, ligando dois grandes centros econômicos do interior da Paraíba e Pernambuco, Caruaru/PE e Campina Grande/PB.

Para realização deste trabalho lançou-se mão de vários procedimentos de investigação. Foi realizada uma revisão da literatura e procedeu-se uma pesquisa documental com a análise

\footnotetext{
${ }^{1}$ A elaboração do Plano Diretor de Queimadas cumpre uma determinação estabelecida pelo Ministério das Cidades, conforme Estatua das Cidades Lei 10.257/2001.

${ }^{2} \mathrm{O}$ município tem uma extensão territorial de $401.8 \mathrm{~km}^{2}$ e que aglutina um contingente populacional de 41.049 habitantes (IBGE, 2015) e população estimada para 2015 de 43.667 habitantes.
} 
do Plano Diretor Participativo de Queimadas (PDPQ). Este é composto pelo: diagnóstico do município, planejamento estratégico e a lei do Plano Diretor. Além disso, utilizou-se também de uma investigação de campo com realização de entrevista semiestruturada com atores-chave dos órgãos de governo, técnicos, cidadãos(ãs) do município.

Além desta introdução e das considerações finais, este trabalho, na segunda seção, apresenta a construção do plano diretor participativo de Queimadas-PB. Esta seção está dividida em três subseções: a primeira apresenta a fase inicial de sensibilização social e institucionalização do projeto Plano Diretor; a segunda mostra o processo de mobilização da sociedade e o levantamento e sistematização das informações; e a terceira mostra a trajetória de sistematização final e pactuação com a sociedade, sendo aprovada a Lei Plano Diretor de Queimadas.

\section{A construção do plano diretor participativo de Queimadas}

O processo de construção do Plano do Diretor de Queimadas teve início em fevereiro do ano de 2005 e término em setembro de 2007, momento da aprovação da Lei do Plano Diretor Participativo de Queimadas (PARAÍBA, 2007) ${ }^{3}$. Conforme os pressupostos e procedimentos participativos anteriormente descritos, o Plano Diretor foi conduzido por um Grupo de Trabalho composto por representantes do Governo Municipal, de organismos estatuais e federais atuantes no município, e por representantes dos demais setores organizados da sociedade. O seu processo de construção concretizou-se mediante as fases e procedimentos ${ }^{4}$ delineados no próprio Projeto de elaboração do Plano Diretor de Queimadas e segundo as diretrizes do Ministério das Cidades. A seguir estão descritas as fases e procedimentos de construção do Plano.

Fase Inicial de Sensibilização, Mobilização Social e Institucionalização do Projeto de Elaboração do Plano

\footnotetext{
${ }^{3}$ Projeto de Lei $n^{\circ} 115 / 2007$ aprovado pela Câmera dos Vereadores.

4 "O que diz o Ministério das Cidades?" Como deve ser o procedimento de construção de um Plano Diretor? Para essa construção é imprescindível participação da população, sendo que essa participação deve ser refletida nos diagnósticos da realidade local. Assim, essa leitura participativa implica nas seguintes etapas: Leituras técnica e comunitária da realidade; formular e pactuar propostas; definir os instrumentos; e modelo de gestão e planejamento para implantar o Plano Diretor.
} 
As primeiras articulações para a construção do Plano Diretor Participativo de Queimadas iniciaram-se no primeiro ano da atual gestão 2005-2008. O primeiro contato foi estabelecido com a Universidade Federal de Campina Grande, que apresentou a obrigatoriedade $^{5}$ do município de Queimadas a construir seu Plano Diretor, assim como a relevância deste para o desenvolvimento municipal (PARAÍBA, 2007).

Após esse primeiro contato estabelecido com a referida Universidade, realizou-se mais uma reunião. Nesta foi planejada a primeira atividade relacionada ao Plano Diretor de Queimadas. Essa atividade foi o "Curso de Capacitação e Gestão de Planos Diretores Participativos”, patrocinado pelo Banco do Brasil e Prefeitura Municipal de Queimadas, sendo realizado num período de três dias.

O curso contou com a presença de lideranças da sociedade civil e política, somando em torno de 35 cursistas. Participaram, então, presidentes de associações do município, diretores de colégios, representantes de instituições religiosas, de fundações, de ONG, do segmento empresariado local, do poder Judiciário, parlamentares locais e o prefeito representando o Executivo, além a presença dos secretários municipais, dentre outras pessoas. $\mathrm{Ou}$ seja, participaram do curso os diferentes grupos sociais e as organizações mais representativas da sociedade civil municipal, muito embora essa se apresente ainda frágil e gelatinosa ${ }^{6}$.

Destaca-se ainda, que esse curso teve a participação de pessoas que compõem o 'capital intelectual' do município e que apresentam experiência profissional em certas áreas do conhecimento ${ }^{7}$. Estas compõem o grupo daqueles chamados "fazedores de opinião",

\footnotetext{
${ }^{5}$ O Estatuto da Cidade estabelece que para elaborar o Plano Diretor o município deve ter, entre outras obrigatoriedades, mais 20 mil habitantes.

${ }^{6}$ Sociedade civil faz parte da noção de Estado ampliado de Gramsci. Assim, sociedade política corresponde ao aparelho do Estado propriamente dito, a sua dimensão coercitiva e de força (Executivo, Legislativo, Justiça, Exército, polícia, etc.) Sociedade civil corresponde a um conjunto de instituições (sindicatos, igrejas, associações, corporações profissionais, cooperativas, clubes de serviço, etc.) através do qual as classes dominantes exercem a sua hegemonia mediante o consentimento das classes e grupos sociais subalternos. Portanto, a sociedade civil corresponde ao conjunto de instituições e organizações ditas privadas, por onde se difundem as ideologias, as ideias, crenças, determinados valores e padrões de conduta. Uma sociedade civil frágil e gelatinosa corresponde a uma sociedade onde a sociedade política, o elemento estatal de coerção e força exerce seu domínio sobre o conjunto da sociedade. O consenso social é obtido mais pela força. As organizações sociais quando não são atreladas à sociedade política, são frágeis e com pouco poder para influenciar adeptos e apoio aos fins que perseguem. Não há, portanto, uma cultura generalizada de cooperação e associativismo cívico (Ver: Coutinho, 1981. p. 87).

${ }^{7}$ Foram classificadas assim: pessoas que apresentam certo grau escolar e conhecimentos específicos e relacionados com a realidade do município: geógrafos, sociólogos, historiadores, economistas, técnicos agrícolas, etc.
} 
multiplicadores de ideias, inovações e saberes. Além disso, de pessoas participantes das organizações sociais e sindicais, como também por aquelas presentes na vida política de Queimadas. Ou seja, essas pessoas podem ser identificadas como aquelas, em nível local, representantes do que o município tem de mais elevado em termos de capital humano (FRANCO, 2001).

Esse curso foi o momento inicial de discussão com as diversas lideranças políticas e comunitárias, gestores escolares e outros, sobre o que era o plano diretor, seus conceitos e procedimentos metodológicos para a sua execução, os seus objetivos, os seus alcances reais.

Em seguida, houve com os participantes a discussão sobre a forma como o Plano Diretor Participativo iria ser construído, enfatizando-se a importância da participação da população na construção deste instrumento de desenvolvimento. O curso foi concluído com a formação do Grupo de Trabalho (GT), posteriormente institucionalizado mediante a portaria do Executivo. Este foi denominado de Conselho Gestor, representando os diferentes setores do poder público, da sociedade civil e da iniciativa privada.

Depois de formado e institucionalizado o Conselho Gestor, foi elaborado o projeto que contém toda a metodologia e procedimentos para elaboração do Plano. Ambos foram apresentados e debatidos em audiência pública, no mês de março. Votados e aprovados na Câmara, o Conselho e o projeto.

Ainda, após o término do curso, foi proposto aos cursistas e componentes do Grupo de Trabalho um pacto em torno da elaboração do Plano: todos se comprometerem a ser multiplicadores dos conhecimentos adquiridos na capacitação, durante a elaboração do Projeto e sua socialização, visando engajamento no processo de outros atores do município. Mas tudo o que foi pensado, acordado, debatido, discutido ali mesmo ficou, só um grupo de pessoas levou o trabalho adiante.

Ressalta-se que, durante os mais de dois anos em que se transcorreu o processo, poucas foram às vezes em que esse órgão - o Conselho - reuniu-se. Aliás, não se reuniu. Assim, a não ser o grupo chamado de Equipe Técnica, da qual faziam parte: assessores, colaboradores e membros deste Conselho. A elaboração do Plano Diretor de Queimadas teve a participação de poucos membros do Conselho e de alguns técnicos na condução de todo o processo. Além disso, as reuniões seguintes, de planejamento das atividades, eram marcadas pela presença de poucas pessoas ligadas à Administração, ao Conselho e às organizações da 
sociedade civil. Esse fato pode expressar uma cultura política local marcada pela falta de associativismo cívico de valores de cooperação, e solidariedade entre as pessoas, de firmação de compromissos e seu cumprimento, ou seja, faltam elementos constitutivos de capital social no sentido de Putnam (1996). Por conseguinte, de capital humano, como retratou Franco (2001), Schultz (1973) e outros. E muito menos se observava elementos constitutivos da soberania popular retratada por Tocqueville (1985), onde o povo discute e se sente parte do processo, pois é de seu interesse debater questões de ordem pública.

No entanto, a Equipe Técnica buscou articular, mediante o Projeto elaborado, apoio financeiro do Ministério das Cidades, e iniciou mediante um plano de trabalho prévio o processo de mobilização e sensibilização social.

Com o Projeto e a elaboração do Plano Diretor em mãos, a equipe buscou o prefeito com o objetivo de encaminhá-lo ao Ministério das Cidades. Esse Projeto continha objetivos, metodologia, cronograma de execução, roteiro de pesquisa, apresentação de resultados e relatórios esperados, o cronograma financeiro, etc. Portanto, além de um plano de trabalho da equipe e da sociedade mobilizada, era também um instrumento de capacitação de recursos.

Nos primeiros três meses a prefeitura garantiu transporte, pessoal de apoio, a produção de material de divulgação e sensibilização, equipamentos, entre outros apoios, além de combustível para o deslocamento até Queimadas, de pelo menos uma vez por semana, do Consultor da Universidade. A esta altura a prefeitura passou por aperto financeiro, tais como as quedas no Fundo de Participação do Município (FPM) e as dívidas acumuladas de serviços prestados com ameaças de corte de energia, de água e telefone. "E já estávamos com o trabalho de mobilização em andamento na Zona Rural" (Entrevista/a 01).

No mais, nessa primeira fase de elaboração do Plano ressaltam-se os cursos de capacitação realizados pelo Ministério das Cidades, através do Instituto de Desenvolvimento Municipal e Estadual, para alguns membros do Grupo de Trabalho, e que serviu de orientação na construção e elaboração do Plano Diretor Participativo. Além desses cursos, já se começou o levantamento das informações pré-existentes sobre o município: dados estatísticos (IBGE e outros órgãos e entidades), documentação histórica e a cartografia existente, teses, dissertações e monografias acadêmicas sobre o município, relatórios de pesquisas e estudos, documentação técnica (planos, projetos e programas) e outras fontes (PARAÍBA, 2007). 
Assim, nessa fase preparatória ocorreram as primeiras articulações para elaboração do Plano. Sendo realizado o curso de capacitação, articularam-se apoios, parcerias e recursos de ordem financeira e material para iniciar o processo; institucionalizou-se o processo, formaram-se os grupos de trabalhos e a coordenação que iria levar os trabalhos à frente, elaborou-se o plano de trabalho, entre outras atividades. Porém, faltou o acúmulo de capital humano e social suficiente capaz de propiciar maior participação nessas atividades iniciais.

A primeira fase foi marcada pela mobilização e sensibilização da comunidade, levantamento de dados e informações junto aos órgãos atuantes no município. Para as reuniões de sensibilização e mobilização social, vários foram os instrumentos utilizados para facilitar a aprendizagem dos envolvidos sobre o que seja o Plano e seus objetivos, como: data show, folders, vídeo do Ministério da Cidade sobre o assunto, divulgação no jornal local. Um dos instrumentos de divulgação das atividades do Plano foi o jornal da cidade: "Queimadas é notícia”, com tiragem mensal de 1000 exemplares. O público estimado e que participou diretamente das reuniões da zona rural foi de 1.150 pessoas ou $6,1 \%$ de um total de 18.986 habitantes da zona rural. Com média de 27 pessoas por reunião.

Essas reuniões aconteciam por regiões e cada uma abrangia em torno de três a quatro comunidades, perfazendo em termos relativos $80 \%$ das comunidades rurais mobilizadas e sensibilizadas, conforme consenso das lideranças participantes da oficina realizada em novembro de 2005. Foram realizadas duas etapas, totalizando 44 reuniões com as comunidades rurais, com a participação dos habitantes e associações locais das regiões, de forma que, em sua grande maioria, as comunidades foram mobilizadas e sensibilizadas quanto à importância do Plano Diretor Participativo.

Nestas reuniões informaram sobre as suas condições de vida, refletiram sobre os problemas enfrentados e construíram propostas de seu futuro desejado. Dentre essas propostas elegeram também as suas prioridades. Na verdade, este levantamento de dados e informações junto às comunidades é resultado de duas etapas de trabalho realizadas na maioria das comunidades rurais do município.

$\mathrm{Na}$ primeira etapa, foram feitas reuniões comunitárias com os moradores em cada setor para sensibilização e mobilização, objetivando construir o Plano Diretor Participativo; na segunda etapa, que contou com a adesão dos moradores e lideranças das comunidades, salienta-se a participação dos moradores no sentido de desenvolver o trabalho de 
levantamento de dados de cada comunidade, proporcionando um espaço democrático no qual os sujeitos participantes puderam falar de seus problemas sem receios, contribuindo enormemente para substancializar socialmente o enfoque participativo.

Destaca-se ainda que o levantamento das informações foi realizado mediante os seguintes procedimentos: formulário entregue à liderança local e com antecedência em relação à segunda reunião, objetivando diagnosticar a realidade; registro de informações e propostas realizadas em reuniões; observação direta e registro de campo; registro em fotografia e vídeo; sistematização por regiões culturais.

Esse levantamento de dados e informações feito junto às comunidades, o cruzamento desses com dados levantados pelos agentes comunitários de Saúde e os fornecidos pela Secretaria de Agricultura, teve como produto a leitura técnica e comunitária: diagnóstico da zona rural. Neste produto está a leitura da zona rural de Queimadas, seus principais problemas, potencialidades e prioridades levantadas e discutidas pela população rural. $\mathrm{Na}$ elaboração deste diagnóstico participaram estudantes universitários, alguns residentes no próprio município.

Em seguida, deveria ter sido realizado um terceiro encontro com as comunidades. Esse encontro consistia em devolver e pactuar com a comunidade o diagnóstico de sua realidade local. No entanto, este momento não foi realizado, provavelmente por dificuldades de recursos financeiros já comentados e/ou de vontade política.

As reuniões na zona rural foram caracterizadas pelo nível significativo de participação. Nessas foram obtidos dados e informações imprescindíveis para realização do diagnóstico da Zona Rural. Destacam-se ainda os dados e informações colhidas junto à Secretaria de Saúde - Programa Saúde na Família, reunidos pelos agentes comunitários de saúde. Além disso, têm-se as informações obtidas via entrevistas com os informantes-chave, com destaque para o assessor do Sindicato dos Trabalhadores Rurais, e que posteriormente veio a ocupar a pasta da Agricultura no município. O mesmo deu informações relevantes e fundamentais para a elaboração do Plano.

Mobilização Social, Levantamento, Análise e Sistematização das Informações

O espaço de tempo que se estende de maio a setembro (2006) é marcado por dificuldades, em termos de condições infraestruturais e de apoio logístico. Além disso, as 
reuniões da zona rural foram comprometidas, devido à ocorrência da seca que atingiu a população do campo, inviabilizando a continuação do trabalho na zona rural. Nesse momento, já havia sido realizada quase a totalidade das reuniões da zona rural, restando poucas a serem feitas, retomadas após a crise de abastecimento de água.

Após essa fase, de outubro (2006) até março (2007) se intensificam os trabalhos do Plano Diretor. Nesse período são feitas as reuniões de mobilização e sensibilização da zona urbana. Para tanto, a rádio comunitária instalada no município (a partir de junho de 2006) foi um instrumento utilizado na divulgação dos trabalhos do Plano, principalmente nos de sensibilização e mobilização da comunidade.

Essa rádio tem uma abrangência significativa no município, cobrindo toda a sede (onde se concentram mais de 17 mil pessoas), além de algumas comunidades rurais. No entanto, esse instrumento não foi explorado a contento, uma vez que para o plano diretor havia um horário de meia hora semanal, somada de algumas divulgações pontuais durante a programação normal da rádio. Este instrumento, ao que parece, teve pouca penetração de público, refletindo em um baixo conhecimento da população sobre o Plano Diretor de Queimadas, principalmente os estudantes.

Porém, um fator a ser destacado é que dentre as cerca de 5 (cinco) rádios FM ouvidas no município, essa rádio comunitária liderava a audiência. $\mathrm{Na}$ verdade, a Coordenação Técnica e a Equipe não souberam explorar o potencial da rádio aumentando o número de demandas, levando ao ar diariamente notícias sobre o andamento do trabalho e interpelando permanentemente a população a participar, tirar dúvidas, a fazer perguntas, a propor e criticar (programas interativos), também não se fez a propaganda do programa de rádio, por mais incipiente que fosse, a fim de aumentar a audiência, panfletando em lugares públicos, no final da missa, etc.

Além da não exploração do potencial de comunicação da rádio comunitária e de outros meios de comunicação, as reuniões realizadas na zona urbana foram bastante limitadas, onde pode ser destacada a reunião com segmento da limpeza urbana, com as associações do Castanho e da Vila, assim como de algumas reuniões setoriais para discutir limpeza urbana, saneamento ambiental, economia, transporte, segurança e outras. Tais limites de participação foram superados, de certa forma, com entrevistas com informantes-chave, com técnicos que atuam em determinados setores da administração pública do município, com experts em 
determinados problemas e temas referentes à prestação de certos serviços, e com as informações levantadas mediante dados estatísticos, documentação técnica, material acadêmico e histórico, a cartografia pré-existente.

Essas reuniões atingiram um público de cerca de 100 pessoas. Em comparação com a zona rural, a zona urbana muito deixou a desejar em termos de reuniões e de mobilização de pessoal. Várias foram as reuniões marcadas com a comunidade urbana e com os seus diversos segmentos a fim de dialogar os problemas da cidade. Essas reuniões que somaram em torno de 10 , e com uma média de 10 pessoas por reunião, foram marcadas pela baixa participação tanto em quantidade como em qualidade. Era uma participação sem substância decorrente da fragilidade do capital humano e social, da cultura política tradicional e atrasada, onde as pessoas não vislumbram uma perspectiva de mudança econômica e social. Nesse sentido, observa-se que o campo da política, da correlação de forças, é um caminho imprescindível para se alcançar o desenvolvimento local sustentável.

De certa forma a relevante presença mobilizadora de certas instituições e entidades no campo, como o Sindicato dos Trabalhadores Rurais de Queimadas, parece ser um fator que pode explicar essa diferença entre zona rural e urbana do município em termos de meios e facilidades de mobilização, habilidades voltadas para a discussão de seus problemas e construção de alternativas para superá-los, mesmo que na zona rural a percepção de problemas ainda seja marcada pelos interesses e soluções mais imediatos.

Assim, os dados e informações necessários para a realização do diagnóstico da zona urbana foram levantados, principalmente junto aos informantes-chave. Somado a esses informantes-chave, o diagnóstico (e o prognóstico) da zona urbana de Queimadas foi feito a partir dos seguintes dados secundários: relatórios da Secretaria Municipal de Saúde, da Vigilância Sanitária e fichas "A" e "B" do Programa de Saúde da Família contendo informação sobre moradias, saneamento básico entre outras; relatório da Secretaria de Cultura, Turismo e Desporto; relatório da Secretaria de Infraestrutura sobre a tipologia e situação das ruas, avenidas e logradouros públicos da cidade; cadastro e dados das secretarias de Finanças e Administração; relatório da empresa contratada para fazer a limpeza urbana e ainda diagnóstico sobre o lixo da cidade, elaborado por esta empresa; diagnóstico e proposta de modernização do Mercado Público e Feira Livre de Queimadas feito pelo SEBRAE (PARAÍBA, 2007).

\section{POLÊM!CA | Revista Eletronica da Veri}


Além desses dados secundários, o IBGE, o Atlas do Desenvolvimento Humano no Brasil do Programa das Nações Unidas para o Desenvolvimento (PNUD), estatísticas da infraestrutura e serviços de saúde do Ministério da Saúde (perfil municipal), estatísticas educacionais - perfil do município / MEC (Ministério da Educação), Ministério do Trabalho e do Emprego (MTE) / CAGED (Cadastro Geral de Empregados e Desempregados); Rede Brasileira de Informação Municipal - Muninet; Banco Estatístico de Queimadas (BEQ) ${ }^{8}$, Anuários Estatísticos da Paraíba (1999; 2000; 2003 e 2004)/ Governo do Estado da Paraíba IDEME (Instituto de desenvolvimento Municipal e Estadual da Paraíba), ofereceram informações que foram compiladas, analisadas e apresentadas em tabelas, quadros e gráficos.

Observou-se ainda uma baixa participação por parte dos funcionários da própria Administração Municipal. Faltou um envolvimento maior de todas as secretarias, assumindo o processo e articulando sinergias para que o plano fosse elaborado. Embora alguns tenham fornecido dados e informações relevantes, como a Secretaria de Saúde, Secretaria de Ação Social, Secretaria de Finanças, Secretaria de Administração, a Secretaria de Educação, a presença dos secretários e de seus prepostos foi bastante limitada.

Dessa forma, a segunda fase de construção constituiu-se de reuniões de sensibilização e mobilização social junto às comunidades, de levantamento de dados e discussão de problemas com a comunidade, concernentes à leitura comunitária da realidade e levantamento de dados e informações (econômicas, sociais e ambientais) rurais e urbanas.

Sistematização Final, Pactuação com a Sociedade e Aprovação da Lei do Plano Diretor

Após essa fase de mobilização e sensibilização da comunidade, de levantamento de dados e informações, iniciou-se a sistematização final do Plano Diretor de Queimadas pela Equipe Técnica, composta em sua maioria por estudantes do município. Em seguida, com base no diagnóstico e na programação (documento das diretrizes estratégicas), foi elaborada uma versão preliminar da Lei do Plano Diretor de Queimadas, que ficou por conta da Assessoria Jurídica da Prefeitura.

Depois que esse documento preliminar foi compatibilizado com os diagnósticos, as propostas, as diretrizes e as estratégias do Plano, essa assessoria encarregou-se da versão final do texto da Lei. Coube-lhe ainda acompanhar o processo legislativo, inclusive,

\footnotetext{
${ }^{8}$ Banco de dados elaborado pela equipe técnica do Plano Diretor do Município, Secretaria Municipal de Desenvolvimento.
} 
disponibilizando-se para eventuais consultas, solicitação de esclarecimentos e emendas. Esse momento teve início em setembro de 2006, com a elaboração do diagnóstico da zona rural, e término em março de 2007.

Assim, o Plano Diretor de Queimadas está estruturado em 02 livros e 05 volumes. O Livro I - Leitura Técnica e Comunitária da Realidade - é composto dos seguintes volumes: Volume I - Diagnóstico da Zona Rural; Volume II - Diagnóstico da Zona Urbana; Volume III - Diagnóstico: Síntese de Leitura Técnica e Comunitária da Realidade; e Volume IV - Anexos de Mapas. Já o Livro II - Plano Estratégico para o Desenvolvimento Sustentável do Município de Queimadas - é composto pelo Volume V-Desafios, Cenários, Diretrizes e Estratégias. Além disso, o Plano Diretor Participativo de Queimadas tornou-se Lei - "Projeto de Lei do Plano Diretor Participativo de Queimadas".

Essa fase pode ser considerada a mais delicada. Em primeiro lugar, porque a prefeitura estava passando por uma crise financeira, impedindo a disponibilidade de recursos para dar continuidade ao processo de elaboração do plano, sendo esse apoio logístico retomado no início de ano. Acrescenta-se que não foram conseguidos junto ao Ministério das Cidades recursos para a elaboração do Plano, ficando a cargo do município todas as despesas. No entanto, o Executivo do município contratou uma consultoria para elaborar o projeto e enviálo ao Ministério para obtenção de recursos, porém essa consultoria não deu resposta.

Em segundo lugar, essa fase pode ser considerada delicada por ter ultrapassado o prazo de entrega do produto, conforme exigia o Estatuto da Cidade (até 10 de outubro de 2006), sendo que a assessoria jurídica entrou com um Termo de Ajustamento de Conduto junto ao Ministério Público (MP). A aceitação pelo Ministério Público permitiu a prorrogação do prazo de entrega. Esse foi o único momento em que o Ministério Público participou das atividades do Plano Diretor de Queimadas.

Assim, o período de setembro (2006) a março (2007) foi dedicado à elaboração dos diagnósticos do município, dos mapas, do plano estratégico e da Lei do Plano Diretor. Para isso, os dados oferecidos pelas secretarias, principalmente pelos informantes-chave, foram fundamentais. Portanto, faltando ainda fazer as correções dos mapas, além da edição do produto final e sua publicação.

O Plano de Queimadas serviu de base para elaboração da Lei. A lei foi encaminhada à Câmara em março e aprovada em setembro de 2007, depois de várias discussões e apreciações 
pelo Legislativo, que basicamente participou do processo nesse momento de aprovação, e na fase inicial, contrariando assim o que diz o Estatuto da Cidade, onde a presença do Legislativo durante todo o processo é fundamental. Faltou ainda, nesse momento de aprovação, uma discussão com os poderes Legislativo, Executivo e a sociedade em seu conjunto, no sentido de se buscar uma pactuação das propostas contidas no Plano. Discussão onde esses atores sociais tomassem conhecimento, pelo menos, daquilo que foi produzido e, ao mesmo tempo, pactuar a execução do Plano Diretor de Queimadas como algo imprescindível para se sair da estagnação econômica, do atraso político e cultural.

Após a construção do Plano Diretor de Queimadas, foi realizada a I Conferência da Cidade. Este era o momento oportuno para apresentação e disseminação dos principais resultados do Plano. Porém, essa oportunidade foi perdida, não sendo levada à frente pelo já então secretário de Desenvolvimento do Município, ex-coordenador-técnico do Projeto de Elaboração do Plano.

Esse momento deveria ser considerado de suma importância, não só como mecanismo de legitimação, mas de apropriação de uma política pública de desenvolvimento, associada à valorização de sentimentos de pertencimento ao território municipal incorporados pelos cidadãos e cidadãs queimadenses. E daí elevar a vontade coletiva para levá-lo à frente.

No mais, pode-se afirmar que até o momento de institucionalização do processo de elaboração do Plano Diretor de Queimadas, esteve presente uma certa quantidade de pessoas representantes de um certo acúmulo de capital social no município e, que a priori, pensava-se que iria continuar com o processo de construção do Plano. Mas apenas se viu um pequeno grupo de pessoas assumir o processo, pelo menos, até a aprovação do Plano pela Câmara Municipal. Esse grupo se desfez. O seu coordenador-técnico foi elevado à função de secretário de Desenvolvimento do Município e o Plano parou por aí.

Essa não continuidade do processo por parte das pessoas integrantes do grupo de trabalho e formadores do Conselho Gestor está relacionada à fragilidade e à insipiência do capital humano e social do município. Observa-se que a falta de cooperação e articulação, de reciprocidade, e o não compromisso das pessoas em torno da continuidade da elaboração do Plano são reflexos de um capital social incipiente, não devidamente mobilizado. Acrescentase a isso uma cultura política cujos valores arraigados são avessos a uma cultura de 
participação, de cooperação, de confiança, de reciprocidade, ou seja, é balizada em valores antirrepublicanos.

Nesse sentido, no decorrer do processo de elaboração do Plano Diretor de Queimadas, percebeu-se que a soberania popular retratada por Tocqueville (1985), quando analisa a vida política da sociedade dos Estados Unidos, onde o povo decide o seu rumo e destino está longe de acontecer em Queimadas. E também está longe de se formar um ambiente democrático e de associativismo cívico, uma comunidade cívica onde a participação cidadã e a solidariedade social são valores fundantes de uma sociedade, conforme retratou Putnam (1996) para o caso do norte da Itália.

\section{Considerações Finais}

O objetivo deste trabalho foi discutir a experiência de construção do Plano Diretor Participativo do Município de Queimadas-Paraíba. Trata-se do Imperativo Lei do Estatuto das Cidades, que regulamenta o artigo 182 da Constituição Federal e que trata da "Política Urbana". Nesse sentido, discutir plano diretor implica em: reacender o debate sobre a importância do planejamento municipal no contexto em que pensar a sustentabilidade (social e ambiental) das cidades torna-se questão chave; segundo, é trazer para o debate público a importância do tema Plano Diretor Participativo, que, ao que tudo indica, está um pouco à margem do debate sobre política urbana.

A reflexão em torno de uma cidade localizada no interior da Paraíba pode trazer inferência e percepções quanto às demais cidades brasileiras de pequeno, médio, grande porte e metrópoles. Quando se fala de planejar o futuro, como afirma Furtado (1999), lançar hipótese sobre o futuro, o diagnóstico dado por esses municípios está relacionado (e é comum aos municípios brasileiros, independente da escala de grandeza), a necessidade de se pensar a participação, os recursos sociais e humanos, o fortalecimento das instituições locais, a sociedade civil organizada, o capital social local, a governança local. Esses elementos são essenciais para superar os problemas que são inerentes ao município (pequenos, médios e grandes) e que são os problemas típicos do subdesenvolvimento.

Assim, as variáveis nesse trabalho, tidas como fundamentais para o progresso econômico e social, para o planejamento e o desenvolvimento local sustentável, portanto, são os recursos humanos ('capital humano'), o capital social e a cultura política. O capital

\section{POLÊM!CA | Revista Eletronica da Ueij}


humano é algo redutível ao indivíduo. No entanto, o capital social não é redutível ao agente. Ele só pode ser usufruído por este enquanto pertencente ao grupo social, podendo obter resultados que não obteria individualmente. A construção e execução do planejamento visando à sustentabilidade das cidades implica fortalecer esses elementos. Nesse sentido, os diagnósticos de Queimadas apontam para a fragilidade de recursos humanos e de capital social, além de uma cultura política adversa e balizada em valores antidemocráticos. Isso impossibilitou a participação efetiva dos cidadãos e cidadãs individual e coletivamente na construção do Plano Diretor.

\section{Referências}

BORDENAVE, Juan E. D. O que é Participação. 8. ed. São Paulo, SP: Brasiliense, 1994.

BOURDIEU, Pierre. Escritos de Educação. 3. ed. Rio de Janeiro, RJ: Vozes, 1998.

BRASIL. Câmara Federal dos Deputados. Lei no. 10.257 de 10 de janeiro de 2001 - Estatuto da Cidade. Regulamenta o Capitulo das políticas urbanas na constituição federal e estabelece as diretrizes para execução de políticas de desenvolvimento urbano, sua principal finalidade é regular o uso da propriedade urbana em prol do bem coletivo, da segurança e do bem estar dos cidadãos, procurando, ainda, do equilíbrio ambiental. Brasília, DF: Senado Federal, 2001

BRASIL. MINISTÉRIO DAS CIDADES. Plano Diretor Participativo: guia para a elaboração pelos municípios e cidadãos. Brasília. 2004.

BRASIL. Senado Federal, Secretaria Especial de Publicações e editorações, Subsecretaria de Edições Técnicas. Constituição da República Federativa do Brasil de 1988. Texto constitucional promulgado em 5 de outubro de 1988, com as alterações adotadas pelas ementas constitucionais de $\mathrm{n}^{\mathrm{os}}$ 1/92 a 44/2004 e pelas Ementas constitucionais de revisão nos 1 a 6/94. Brasília, DF: Senado Federal, 1988.

CASTELLS, Manuel. A Era da Informação: Economia, Sociedade e Cultura. Vol. I: A Sociedade em Rede. Rio de Janeiro: Paz e terra, 1999.

COUTINHO, Carlos Nelson. Gramsci. Porto Alegre: L \& M, 1981.

FRANCO, Augusto. Capital Social. Leituras de Tocqueville, Jacobs, Putnam, Fukuyama, Maturana, Castells e Levy. Rio de Janeiro: Rocco, 2001.

FUKUYAMA, F. Social capital and civil society. Internacional Monetary Fund (IMF). Working Paper. WP/00/74, april, 2000.

FURTADO, Celso. O Longo Amanhecer: reflexões sobre a formação do Brasil. Rio de Janeiro: Paz e Terra, 1999.

INSTITUTO BRASILEIRO DE GEOGRAFIA E ESTATÍSTICA. Cidades@. 2015. Disponível em: http://www.cidades.ibge.gov.br/xtras/home.php. Acesso em: 27 de setembro de 2015.

LIMA, S. J. Entrevista 01. [nov. 2007]. Entrevistador: Danilo Raimundo de Arruda. Queimadas/PB, 2007.1 arquivo.

\section{POLÊM!CA | Revista Eetrônica da veri}


MINISTÉRIO DAS CIDADES. Plano Diretor Participativo: guia para a elaboração pelos municípios e cidadãos. Brasília. 2004.

PARAÍBA. Plano Diretor Participativo de Queimadas. Queimadas/PB: Prefeitura Municipal de Queimadas. Volumes: I, II, III, IV e V. 2007.

PARAÍBA. Projeto de Lei do Plano Diretor Participativo de Queimadas ( ${ }^{\circ}$ 115/2007). Queimadas/PB. Prefeitura Municipal de Queimadas. 2007.

PUTNAM, Robert D. Comunidade e Democracia: a experiência da Itália moderna. Rio de Janeiro: Editora Fundação Getúlio Vargas, 1996.

SCHULTZ, Theodore W. O capital humano: investimentos em educação e pesquisa. Rio de Janeiro: Zahar, 1973.

TOCQUEVILLE, Alexis. A Democracia na América. São Paulo: Abril Cultural, 1985.

Recebido em: 05/10/2015.

Aceito em: 16/10/2015. 